\title{
Elevation-dependent warming in mountain regions of the world
}

\author{
Mountain Research Initiative EDW Working Group`
}

\begin{abstract}
There is growing evidence that the rate of warming is amplified with elevation, such that high-mountain environments experience more rapid changes in temperature than environments at lower elevations. Elevation-dependent warming (EDW) can accelerate the rate of change in mountain ecosystems, cryospheric systems, hydrological regimes and biodiversity. Here we review important mechanisms that contribute towards EDW: snow albedo and surface-based feedbacks; water vapour changes and latent heat release; surface water vapour and radiative flux changes; surface heat loss and temperature change; and aerosols. All lead to enhanced warming with elevation (or at a critical elevation), and it is believed that combinations of these mechanisms may account for contrasting regional patterns of EDW. We discuss future needs to increase knowledge of mountain temperature trends and their controlling mechanisms through improved observations, satellite-based remote sensing and model simulations.
\end{abstract}

\begin{abstract}
$t$ is well known that the rate of temperature change with increased levels of greenhouse gases in the atmosphere is amplified at high latitudes, but there is growing evidence that the rate of warming is also amplified with elevation, such as in mountain environments. This elevation-dependent warming (EDW) has important implications for the mass balance of the high-altitude cryosphere and associated runoff; for ecosystems and farming communities in high-mountain environments; and also for species that reside in restricted altitudinal zones within a mountain range. However, because of sparse high-elevation observations, there is a danger that we may not be monitoring some regions of the globe that are warming the most. Here we review the evidence for EDW and examine the mechanisms that may account for this phenomenon. We conclude with a strategy for future research to reduce current uncertainties and to ensure that the changes taking place in remote high-elevation regions of the planet are adequately observed and accounted for.
\end{abstract}

\section{Evidence for elevation-dependent warming}

In theory, it should be simple to document the rate and geographical pattern of warming with elevation over recent decades. However, many factors make it extremely difficult to determine the rate of warming in mountainous regions. First and foremost, long-term meteorological stations (with more than 20 years of records) are extremely sparse at high elevations. For example, in the GHCNv3 database of homogenized stations, out of 7,297 stations, only 191 (3\%) are above 2,000 $\mathrm{m}$ and 54 (0.7\%) above 3,000 $\mathrm{m}$, and long-term data are simply non-existent above $5,000 \mathrm{~m}$ in any mountain range ${ }^{1}$. Unlike in the Arctic, which is relatively homogenous, mountain temperatures suffer from extreme local variability due to factors such as topography, slope, aspect and exposure. Of the high-elevation stations in the GHCNv3 database, very few are on isolated peaks or plateau, and most observations within high-mountain regions are taken from valleys with distinct microclimates prone to cold air drainage $e^{2-4}$, which makes it hard to separate noise from trend.

Evidence for EDW could also come from satellite data, atmospheric reanalysis or model studies, but these sources have limitations. Satellites generate surface ('skin') temperature, which is not generally recorded at surface meteorological stations. Moreover, satellite data are of limited duration ${ }^{5}$ and are not well validated in high-elevation regions where clouds are common. Reanalysis data sets are heavily dependent on free air (not just surface) data, and they are not homogenized for climate trend analysis. Models generally have poor spatial resolution and require observational data for validation, making it difficult to be sure that simulations are accurate.

Notwithstanding these limitations, there have been many studies that have attempted to identify $y^{6,7}$ and quantify EDW (Table 1). More detail concerning individual studies (including metadata) is given in the Supplementary Information. Here we summarize the literature as a whole. A majority of studies suggest that warming is more rapid at higher elevations but there are a number of studies that show either no relationship or a more complex situation (Table 1). This is particularly true for observational studies, which are in less agreement than model simulations. This may be because most models integrate trends over a long time period (typically up to the end of the twenty-first century), when EDW may become more widespread than it has been so far. It is also noticeable that minimum temperatures show a stronger tendency towards EDW than maximum temperatures, and so separate mechanisms may be at work during the day and night. Of the studies listed in Table 1, there are relatively few global studies that have examined surface $(\sim 2 \mathrm{~m})$ temperature data for evidence of $\mathrm{EDW}^{8-11}$.

There has also been a lack of consistency in the methods and data used to quantify the rate and patterns of warming. Differences in the time periods examined, the stations compared, the elevational range selected, and the temporal resolution of the data (that is, daily versus monthly or annual temperatures) all vary (see Supplementary Information) and thus contribute to differences in trends. Many studies are relatively short (less than 50 years) and so strong interdecadal variability often contributes to observed trends ${ }^{12}$. Although some data homogenization has been achieved for station records in Europe and North America, there is a particular problem with the mountain data in the tropics, which is both sparse and inhomogeneous.

The most striking evidence for EDW is from Asia. Yan \& $\mathrm{Liu}^{13}$ investigated warming trends (1961-2012) using 139 stations on and around the Tibetan Plateau, the most extensive high-elevation area in the world. Figure 1 shows mean warming rates $\left({ }^{\circ} \mathrm{C}\right.$ per decade) for contrasting periods for stations in 500-m-wide altitudinal 
Table 1 | Results from studies that investigated elevational gradient in warming rates (updated from ref. 25).

\begin{tabular}{|c|c|c|c|c|c|c|}
\hline \multirow[b]{2}{*}{ Elevational gradient in the warming rate } & \multicolumn{3}{|c|}{ Observations } & \multicolumn{3}{|c|}{ Models } \\
\hline & $T_{\min }$ & $T_{\max }$ & $T_{\text {avg }}$ & $T_{\min }$ & $T_{\max }$ & $T_{\text {avg }}$ \\
\hline Increases with elevation & $\begin{array}{l}\text { Annual }{ }^{23,8 a, 86} \\
\text { Winter }^{23,70 g, 45} \\
\text { Spring } \\
\text { Autumn } \\
\text { Al,83e }^{47}\end{array}$ & $\begin{array}{l}\text { Annual }{ }^{23,81} \\
\text { Summer }\end{array}$ & $\begin{array}{l}\text { Annual } 76,5 e, 80 b, 10 c, 11,75 \\
\text { All seasons } \\
\text { Winter }^{87}\end{array}$ & $\begin{array}{l}\text { Annual }{ }^{45} \\
\text { Winter }^{45,43,72,74} \\
\text { Spring } \\
45,43\end{array}$ & $\begin{array}{l}\text { Winter }^{43} \\
\text { Spring }^{43} \\
\text { Autumn }^{72}\end{array}$ & $\begin{array}{l}\text { Annual }{ }^{79} \\
\text { Winter }^{30,69,14,79} \\
\text { Spring }^{30,14,79} \\
\text { Summer }^{86}\end{array}$ \\
\hline Decreases with elevation & Winter ${ }^{23}$ & Winter ${ }^{47}$ & $\begin{array}{l}\text { Annual }{ }^{77,84} \\
\text { Winter }^{30 g} \\
\text { Autumn }^{30 g}\end{array}$ & Summer ${ }^{84}$ & & $\begin{array}{l}\text { Annual }{ }^{73 f} \\
\text { Spring } \\
\text { Autumn } \\
\text { Auff }\end{array}$ \\
\hline No significant gradient & - & Annual ${ }^{68}$ & $\begin{array}{l}\text { Annual }{ }^{30,85,71 d, 82} \\
\text { All seasons }^{44,85}\end{array}$ & - & & Annual ${ }^{30}$ \\
\hline $\begin{array}{l}\text { No significant gradient but largest warming } \\
\text { rates at an intermediate elevation }\end{array}$ & - & Annual ${ }^{78}$ & $\begin{array}{l}\text { Annual99,43c } \\
\text { Spring } \\
30 g\end{array}$ & - & & Spring ${ }^{30}$ \\
\hline
\end{tabular}

Superscript letters accompanying references indiciate: ${ }^{N}$ No significant gradient but greater warming at higher elevations relative to regions between $0-500 \mathrm{~m} ;{ }^{b}$ radiosonde data, clearest signal in the tropics; ${ }^{\mathrm{c}} 65 \%$ of the regional groups examined showed fastest trends at highest elevations and $20 \%$ showed fastest trends at intermediate elevations; ' high-elevation trends based on borehole data; ${ }^{\text {' }}$ satellite-derived temperature estimations; freanalyses; gridded data.

bands starting at $1,000 \mathrm{~m}$. Systematic increases in warming rate with elevation are uncovered for annual mean temperature, and warming rates have increased in recent decades (Fig. 1a). Mean minimum temperatures also show EDW on an annual basis (Fig. 1b), as do mean temperatures in autumn (Fig. 1c) and winter (Fig. 1d). There was no strong elevational effect in other seasons, or for mean maximum temperatures, a result that is consistent with findings in other areas.

Model simulations have also been used to identify EDW, both in historical and future projections $s^{14-16}$. Most general circulation models (GCMs) indicate that EDW in the free atmosphere is a characteristic of low-latitude regions, with the IPCC Fifth Assessment Report including a maximum warming signal around $400-200 \mathrm{hPa}$ in the representative concentration pathway (RCP) scenarios, for example (see Fig. 12.12 of ref. 17). This EDW does not extend into the mid- and high latitudes, and in most models warming is concentrated at the surface $(>800 \mathrm{hPa})$, especially in the Northern Hemisphere. Few studies have been specifically designed to investigate the geographical pattern of and processes associated with EDW at the mountain surface, which is sometimes dissimilar to the free atmosphere ${ }^{18}$. The climate response to greenhouse-gas forcing within complex mountain topography can only be adequately captured using models with a spatial resolution of $5 \mathrm{~km}$ or less ${ }^{19}$, which generally implement non-hydrostatic equations for the atmosphere. Such simulations can be done for both historical case studies (using reanalyses as boundary forcing) and future scenarios (using GCM projections); and although the computational demands are high at present, novel and selective experimental designs to conduct studies at such high resolutions are feasible ${ }^{20,21}$. Of those modelling studies that have identified EDW, the most common explanation is associated with the snowalbedo feedback mechanism, which is often discussed in terms of the upslope movement of the zero-degree isotherm ${ }^{14}$, although other factors such as elevation-dependent changes in cloud cover and soil moisture have also been suggested as possible forcings ${ }^{22}$.

Regional variability in EDW could also be influenced by interannual to decadal variability in large-scale circulation; such as the El Niño/Southern Oscillation (ENSO), North Atlantic Oscillation (NAO), Pacific Decadal Oscillation (PDO), and so on. For instance, it has been found that during positive NAO winters in the late 1980s and early 1990s, there was enhanced warming at high elevations in the European Alps, associated with warm wet winters ${ }^{23}$. This pattern was reversed during years with a negative NAO index. In the tropical Andes, increasing freezing level heights between 1958 and 1990 were related to El Niño conditions (higher sea surface temperatures in the eastern tropical Pacific) and attendant changes in clouds and atmospheric water vapour, which can drive regional variability in $\mathrm{EDW}^{24}$. More recent work has shown how tropical high-elevation temperatures are modulated by $\mathrm{ENSO}^{12}$. Because of all of these factors, we can only say at present that there is evidence that many, but not all, mountain ranges show enhanced warming with elevation. Understanding the physical mechanisms that drive EDW is therefore essential to explain the regional variations, as discussed below.

\section{Hypotheses and mechanisms for EDW}

Temperature change at the Earth's surface is primarily a response to the energy balance, and therefore factors that preferentially increase the net flux of energy to the surface along an elevation gradient would lead to enhanced warming as a function of elevation. Here we discuss various mechanisms and processes that have been linked to $\mathrm{EDW}^{25}$. The physical shape of the associated elevational signal is shown in Fig. 2.

Albedo. Snow-albedo feedback is an important positive feedback in Arctic amplification ${ }^{26,27}$, but it is also relevant in snow-dominated high-elevation regions ${ }^{14,28,29}$ where the seasonal timing of snow cover varies with elevation, and maximum warming rates commonly occur near the annual $0{ }^{\circ} \mathrm{C}$ isotherm ${ }^{9,30}$. In the Swiss Alps, the daily mean 2-m temperature of a spring day without snow cover is $0.4{ }^{\circ} \mathrm{C}$ higher than one with snow cover ${ }^{31}$ (mean value for 1961-2012). The current snowline, which varies in elevation across different mountain ranges, is expected to retreat to higher elevations as the overall climate system warms. The definition of the snowline is not as simple as might be expected: different studies in the Alps have yielded contrasting heights ${ }^{32-34}$. The elevation dependency of snow cover duration (and also of the snow/rain ratio) is nonlinear, so the rate of snowline retreat may increase as temperatures rise ${ }^{35}$. This will result in significant increases in the surface absorption of incoming solar radiation around the retreating snowline (approximated by the $0{ }^{\circ} \mathrm{C}$ isotherm), initially causing enhanced warming at that elevation ${ }^{36}$. As the snowline migrates upslope, this effect will extend to increasingly higher elevations (Fig. 2a). A similar process is expected to result from an upslope migration of treelines, owing to the accompanying reduction in surface albedo through greening ${ }^{37,38}$. Changes in the ratio of snow to rain are also likely to occur over a wider elevation band, as already noted in the Tibetan Plateau/Himalaya region, where 
a

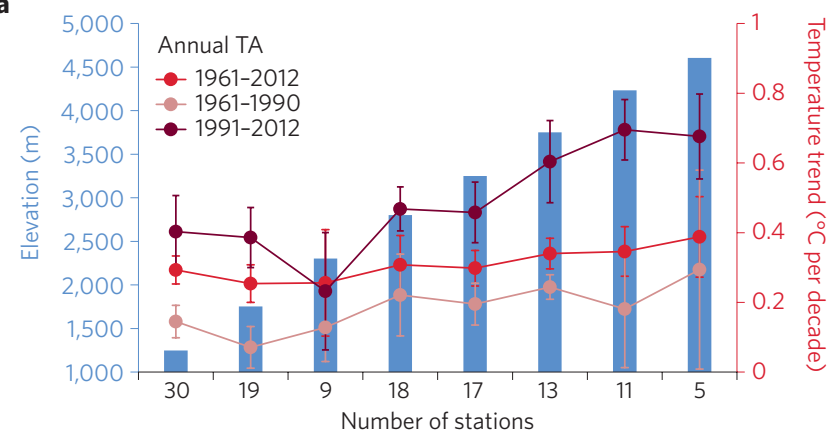

C

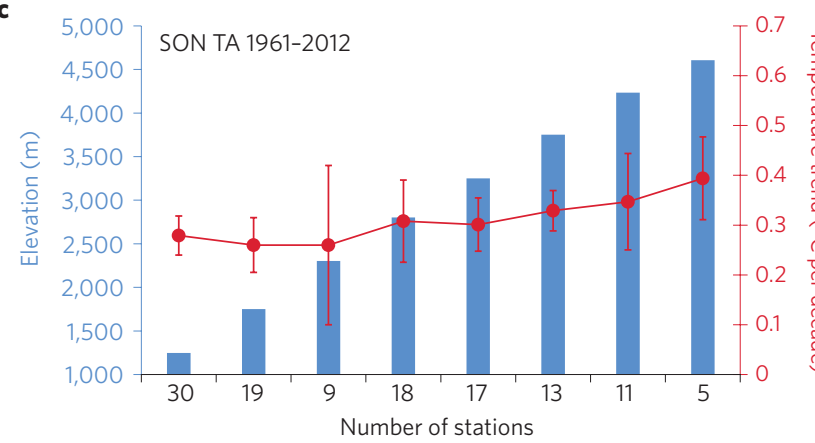

b

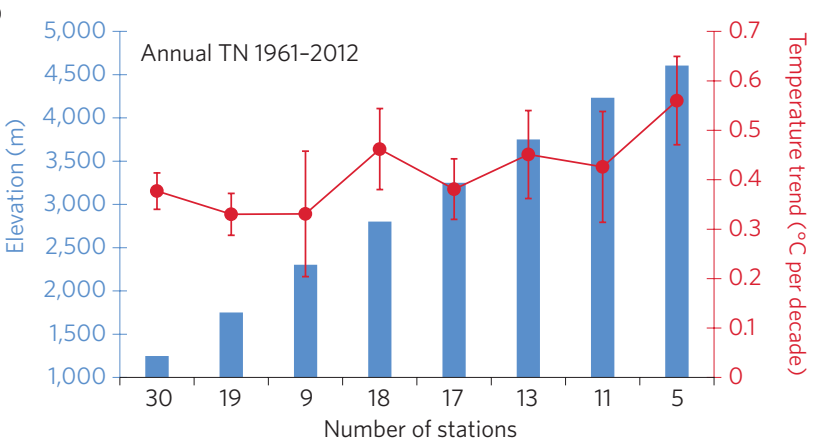

d

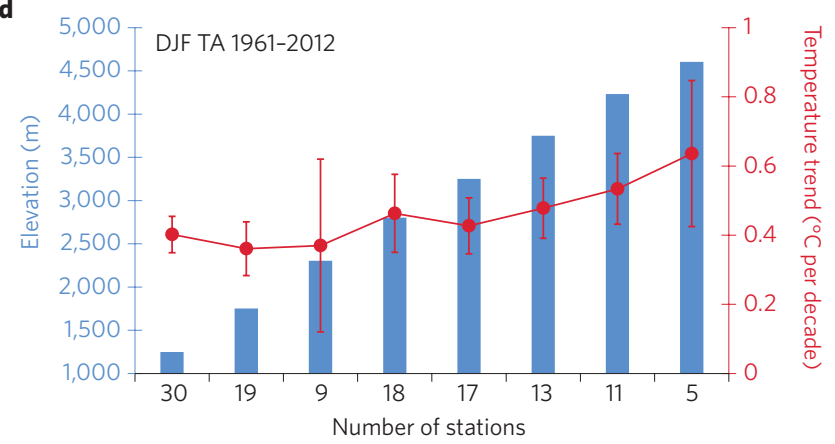

Figure 1 | Elevation-dependent warming over and around the Tibetan Plateau. a, Annual mean surface air temperature (TA) over 3 time periods. b, Annual mean minimum temperature (TN) from 1961-2012. c, Mean autumn (September-November, SON) surface temperature from $1961-2012$.

d, Mean winter (December-February, DJF) surface temperature from 1961-2012. Bars represent elevation and trend magnitude is plotted on the $y$ axis according to the 8 elevation ranks of 122 stations. The presentation format is similar to ref. 76 for ease of comparison. Error bars are based on $95 \%$ confidence intervals around the mean. The vertical scale for winter warming rate (d) and annual warming rate (a) have been adjusted to reflect the more rapid warming.

the snow cover season has shortened and more precipitation is now falling as rain $^{39-41}$. The snow-albedo mechanism has a stronger influence on maximum than minimum temperatures because of the increase in absorbed solar radiation, as noted by Kothawale et al. ${ }^{42}$, who compared maximum and minimum temperature trends in the western Himalayas between 1971 and 2007. A regional climate model study also found EDW in the Alps and suggested that the increasing influence of the snow-albedo feedback mechanism, primarily during spring and summer, was responsible $^{14}$. The specific temperature response $\left(T_{\min }\right.$ versus $\left.T_{\max }\right)$ will depend on soil moisture; if the increased surface shortwave absorption is balanced by increases in sensible heat fluxes (rather than latent heat fluxes), the response will be more prominent in $T_{\max }$ (rather than $T_{\min }$ ). A more amplified response has been found in $T_{\min }$ relative to $T_{\max }$ in lower-elevation regions $(1,500-2,500 \mathrm{~m})$ of the Colorado Rocky Mountains during winter, using regional climate models ${ }^{43}$. This was caused, in part, by the increases in the absorbed solar radiation at the surface, primarily balanced by increases in the latent heat fluxes caused by the increases in surface soil moisture from snowmelt.

Clouds. Observations of long-term changes in clouds and cloud properties are sparse, particularly in high-elevation regions, and there are few studies that discuss how changes in clouds might affect $\mathrm{EDW}^{44,45}$. Changes in cloud cover and cloud properties affect both shortwave and longwave radiation and thus the surface energy budget. They also affect warming rates in the atmosphere through condensation. A band of enhanced warming caused by latent heat release is expected near the condensation level, which could be further augmented by higher atmospheric water vapour content ${ }^{24}$ resulting from global warming (Fig. 2b). If the condensation level rises (which may occur if temperatures also rise and dew-point depression increases at sea level), then a band of reduced warming would occur immediately below the new cloud-base (dotted line, Fig. 2b) with enhanced warming above. Thus, the overall implications of a warmer and moister atmosphere support enhanced warming at high elevations $s^{46,47}$. For the Tibetan Plateau between 1961 and 2003, decreasing cloud cover during the daytime, but increasing low-level clouds at night, has caused minimum temperatures to increase $e^{48}$. Using weather stations and high-resolution climate model output, Liu et $\mathrm{al} .{ }^{45}$ found that cloud-radiation effects were partly responsible for EDW on the Tibetan Plateau. A similar response was observed in the $\mathrm{Alps}^{23}$ with an altitudinal dependence of temperature anomalies, except that lower elevations were affected by changes in fog and stratus clouds.

Water vapour and radiative fluxes. Processes associated with the relationships between longwave radiation, moisture and thermal regimes along an elevation gradient are expected to lead to EDW. These include: (i) the sensitivity of downward longwave radiation (DLR) to specific humidity $(q)$; and (ii) the relationship between temperature and outgoing longwave radiation (OLR). DLR increases in response to increasing $q$; however, this relationship is nonlinear (Fig. 2c) with substantially higher sensitivities at low levels of $q$, especially below $2.5 \mathrm{~g} \mathrm{~kg}^{-1}$, which are found in many high-elevation regions ${ }^{47,49,50}$. These high sensitivities occur because, below a certain $q$ threshold, the air becomes optically under-saturated in the longwave water vapour absorption lines. In such conditions, small water vapour increases can have a substantial influence on DLR, resulting in a significantly greater warming response at higher elevations. Both observations ${ }^{47,51}$ and climate model simulations ${ }^{16,29}$ suggest that this mechanism has contributed to EDW. In the Alps, the DLR-q sensitivity is particularly 
a

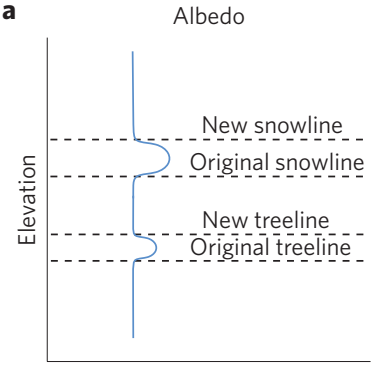

$\mathrm{dT} / \mathrm{dt}$

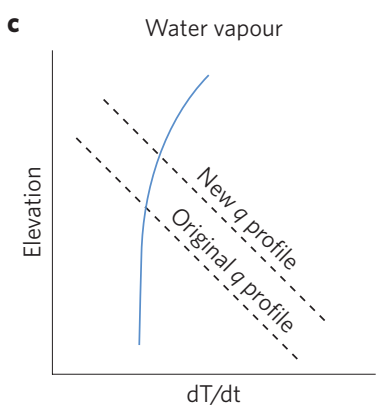

e

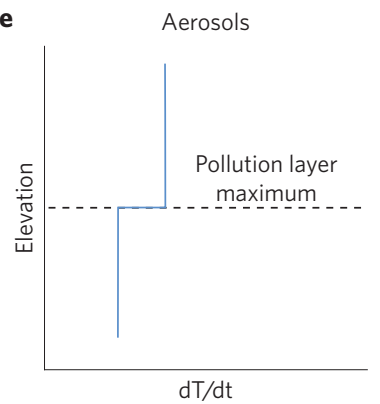

Figure $\mathbf{2}$ | Schematic of the relative vertical profile in atmospheric warming expected to result from various mechanisms. The details of each mechanism are discussed in the main text. The $x$ axis represents the rate of warming (dT/dt or expected trend magnitude). The curves are relative in that the absolute value on the $x$ axis is unimportant; the shape of the signal in comparison with elevation is the principal focus.

high for $q$ below $5 \mathrm{~g} \mathrm{~kg}^{-1}$, conditions that are more likely at higher elevations and during the cold season in the extra-tropics ${ }^{49}$. A similar finding was also reported for the Colorado Rocky Mountains $s^{52}$, which also showed that clouds have a limited effect on DLR- $q$ sensitivities.

Another mechanism related to radiative fluxes is a direct consequence of the functional shape of blackbody emissions. For a given heat flux exchange (for example, an increase in OLR), this relationship will result in a larger temperature change at lower temperatures $^{53}$. OLR is one of the major mechanisms through which the land surface loses heat and is proportional to the fourth power of temperature (the Stefan-Boltzmann law). Therefore, for a given change in radiative heating, higher elevations will experience enhanced warming rates along an elevational gradient. This effect will not be sensitive to seasons or geography (Fig. 2d).

Aerosols. Most of the atmospheric loading of aerosol pollutants (for example, atmospheric brown clouds and associated black carbon in Asia) is concentrated at relatively low elevations (below $3 \mathrm{~km})^{54}$, which would be expected to decrease the flux of shortwave radiation to lower mountain slopes (known as the surface dimming effect), but have limited or no effects on higher mountains above the polluted layer (Fig. 2e). However, there has been little systematic investigation of the elevational signal of anthropogenic pollutants in mountain regions. High levels of black carbon have been found at 5,000 $\mathrm{m}$ in the Himalayas during the pre-monsoon season ${ }^{55}$, but it is unclear whether such conditions reflect local up-valley transport or more regional conditions. Certainly, aerosols are transported to elevations above $10 \mathrm{~km}$ over Tibet and much of central Asia during convective monsoon activity ${ }^{56,57}$.

Black carbon affects the radiation budget in two ways. It absorbs radiation (principally in the mid- to lower troposphere) and decreases the surface albedo when deposited on snow ${ }^{58-60}$. It has been suggested that black carbon could account for half of the total warming in the Himalayas during the past several dec$\operatorname{ades}^{54}$. Aerosols like dust depend on other factors, such as landuse change. For example, the disturbance of ground cover in the western US causes dust to be readily transferred into the atmosphere and transported by wind into the mountains where it settles on snow, reduces albedo and leads to enhanced warming at higher elevations ${ }^{61}$.

Combination of mechanisms. The resulting response to all these factors and their interactions is complex. Some factors will be more influential than others in certain parts of the globe and at certain times of year, and this may partly account for the differences in EDW reported in Table 1. Albedo feedback will be strongest wherever snowlines are retreating, but their elevational focus will be narrowed (and more prominent) in the tropics where there is reduced seasonal variation in snowline elevation. The cloud feedback (latent heat release) will be enhanced at high temperatures and is therefore also dominant in the tropics, particularly in the free atmosphere where it is responsible for amplified warming in most IPCC simulations ${ }^{62}$. In contrast, aerosol loading is concentrated in mid-latitudes (particularly Asia) and the water vapourradiative feedbacks are enhanced at low temperatures so should be dominant at higher latitudes, at night and in winter. All the physical processes point to either an expected increase in warming with elevation, or an enhanced band of sensitivity that will move upslope with time. Although the physical reasons for the existence of EDW are strong, the observational evidence for EDW is not yet as clear cut. Therefore, we urgently need to develop a more systematic method of climate monitoring at high elevations to quantify the extent of the phenomenon and its spatial variability.

\section{Future needs}

The surface in situ climate observing network needs to be expanded to cover data-poor regions, and to include more variables. Air temperature observations at ground stations are essential but many high-altitude areas (for example, greater than 4,000 m) are still heavily under-sampled. The longest detailed ultra-high-elevation records (higher than 5,000 m) include those on Kilimanjaro and Quelccaya, but these are only now just over 10 years long ${ }^{63}$. Therefore, special efforts should be made to extend observations upwards to the highest summits, with transects of highly accurate instruments (as used, for example, in the National Oceanic and Atmospheric Administration (NOAA) Climate Reference Network) measuring a broad array of variables (such as humidity, radiation, clouds, precipitation, soil moisture and snow cover, besides temperature) to fill the pronounced high-altitude observational gap. Targeted field campaigns should be devised to detect and better understand EDW in areas where its signal is expected to be strongest (see the discussion above on mechanisms). For example, radiation measurements, together with measurements of humidity, albedo, temperature and soil moisture, could be focused around the treeline, and above and below the snowline in areas with high interannual variation in snowline position, to determine the partitioning of energy fluxes; black carbon and other aerosols should be monitored more widely to determine their relationship to 
other meteorological parameters (see Supplementary Information for more detail).

Because high-elevation trends can be influenced by decadal-scale changes in circulation, long-term data sets ( $>50$ years) may be needed to extract the EDW signal. Thus, in addition to new observations, we need to locate and evaluate observational data that already exist. This may also include high-resolution palaeoclimate data sets. Much high-elevation climate data are largely inaccessible due to poorly managed data archives in different countries, and there have been only limited efforts to create homogenous high-elevation global data sets. Powerful methods for homogenizing climate data are available (see, for example, http://www.homogenisation.org) but better metadata (for example, station characteristics such as topography) and information on station location and instrument changes need to be incorporated more systematically into high-elevation data sets. Finally we need agreed metrics to measure and quantify EDW once data are collected.

To further overcome limitations arising from the sparseness of in situ stations in under-sampled high-altitude regions, spatially continuous remotely sensed land surface temperature (LST) data from satellites could be used ${ }^{5}$. The availability of new products based on a combination and/or merging of remotely sensed land surface temperature and in situ air temperature data represents an essential ingredient for the study of EDW and should be strongly encouraged for studies of high-mountain regions. However, validation of satellite data (LST) with current high-elevation air temperature records is critical, and new approaches may be required to resolve temperature trends in complex topographic settings where cloud cover is often present.

To complement an enhanced observational network, both global and fine-scale regional climate model simulations (historical and future) should be analysed for sensitive regions in order to: (i) investigate how well the models represent the specific climate variables as well as the interactions among them; and (ii) identify and quantify the processes which are responsible for EDW. For regional studies, both statistically and dynamically downscaled model simulations may be useful, although multi-decadal simulations will be needed to fully investigate future projections of EDW. Models can also be used to perform sensitivity studies to investigate and quantify the role of specific climate variables. For example, although models have been used to quantify the magnitude of the snow/albedo feedback in the Arctic ${ }^{64-66}$, there has been little attempt to do this in high-elevation regions ${ }^{16}$. By doing a detailed analysis of regional energy budgets, one can potentially determine which energy budget component(s) are most responsible for temperature change and then in turn which climate variable(s) are most responsible for the change in energy budget. However, many of the variables interact with each other, and it can be difficult to untangle the dependencies. There have been statistical analyses that attempt to quantify specific processes (for example, Naud et al. ${ }^{52}$, who used a neural network method to quantify the sensitivity of downward longwave fluxes to changes in water vapour) but the dependencies among different variables remains problematic, and new techniques are still required to improve such analyses.

\section{Conclusion}

EDW is a poorly observed phenomenon that requires urgent attention, to ensure that potentially important changes in high-mountain environments are adequately recorded by the global observational network. More rapid changes in high-mountain climates would have consequences far beyond the immediate mountain regions, as mountains are 'water towers' and the major source of water for large populations in lower elevation regions ${ }^{67}$. The social and economic consequences of enhanced warming in mountain regions could therefore be large, and this alone justifies that close attention should be paid to the issue. In addition, mountains provide habitat for many of the world's rare and endangered species, and the presence of many different ecosystems in close proximity enhances the ecological sensitivity of mountains to environmental change. Understanding how future climatic changes may impact the zonation of ecosystems in high-mountain regions provides an equally compelling argument for understanding this issue further. A strategy that combines a network of field observations, satellite remote sensing and high-resolution climate modelling is required to fully address the problem.

Received 12 November 2014; accepted 6 February 2015; published online 23 April 2015

\section{References}

1. Lawrimore, J. H. et al. An overview of the Global Historical Climatology Network monthly mean temperature data set, version 3. J. Geophys. Res. 116, D19121 (2011).

2. Whiteman, C. D. Mountain Meteorology: Fundamentals and Applications. (Oxford Univ. Press, 2000).

3. Barry, R. G. Mountain Weather and Climate 3rd edn (Cambridge Univ. Press, 2008).

4. Pepin, N. C. Daly, C. \& Lundquist, J. The influence of surface versus freeair decoupling on temperature trend patterns in the western United States. J. Geophys. Res. 116, D10109 (2011).

5. Qin, J., Yang, K., Liang, S. \& Guo, X. The altitudinal dependence of recent rapid warming over the Tibetan Plateau. Climatic Change 97, 321-327 (2009).

6. Barry, R. G. Mountain climatology and past and potential future climatic changes in mountain regions: a review. Mountain Res. Devel. 12, 71-86 (1992).

7. Barry, R. G. in The State of the World's Mountains: A Global Report (ed. Stone, P. B.) 359-380 (Zed Books, 1992).

8. Diaz, H. F. \& Bradley, R. S. Temperature variations during the last century at high elevation sites. Climatic Change 36, 253-279 (1997)

9. Pepin, N. \& Lundquist, J. Temperature trends at high elevations: patterns across the globe. Geophys. Res. Let. 35, L14701 (2008).

10. Ohmura, A. Enhanced temperature variability in high-altitude climate change. Theor. Appl. Climatol. 110, 499-508 (2012).

11. Wang, Q., Fan, X. \& Wang, M. Recent warming amplification over high elevation regions across the globe. Clim. Dynam. 43, 87-101 (2014).

12. Diaz, H. F., Bradley, R. S. \& Ning, L. Climatic changes in mountain regions of the American Cordillera and the Tropics: historical changes and future outlook. Arct. Antarct. Alp. Res. 46, 735-743 (2014).

13. Yan, L. \& Liu, X. Has climatic warming over the Tibetan Plateau paused or continued in recent years? J. Earth Ocean Atmos. Sci. 1, 13-28 (2014).

14. Giorgi, F., Hurrell, J., Marinucci, M. \& Beniston, M. Elevation dependency of the surface climate change signal: a model study. J. Clim. 10, 288-296 (1997).

15. Bradley, R. S., Keimig, F. T., \& Diaz, H. F. Projected temperature changes along the American cordillera and the planned GCOS network. Geophys. Res. Lett. 31, L16210 (2004).

16. Rangwala, I. Amplified water vapour feedback at high altitudes during winter. Int. J. Climatol. 33, 897-903 (2013).

17. Collins, M. et al. in Climate Change 2013: The Physical Science Basis (eds Stocker, T. F. et al.) 1029-1136 (IPCC, Cambridge Univ. Press, 2013).

18. Pepin, N. \& Seidel, D. J. A global comparison of surface and free-air temperatures at high elevations. J. Geophys. Res. 110, D03104 (2005).

19. Rasmussen, R. et al. High-resolution coupled climate runoff simulations of seasonal snowfall over Colorado: a process study of current and warmer climate. J. Clim. 24, 3015-3048 (2011).

20. Rasmussen, R. et al. Climate change impacts on the water balance of the Colorado headwaters: high-resolution regional climate model simulations. J. Hydromet. 15, 1091-1116 (2014).

21. Kendon, E. J. et al. Heavier summer downpours with climate change revealed by weather forecast resolution model. Nature Clim. Change 4, 570-576 (2014).

22. Kotlarski, S., Bosshhard, T., Luthi, D., Paul, P. \& Schar, C. Elevation gradients of European climate change in the regional climate model COSMO-CLM. Climatic Change 112, 189-215 (2012).

23. Beniston, M. \& Rebetez, M. Regional behavior of minimum temperatures in Switzerland for the period 1979-1993. Theor. Appl. Climatol. 53, 231-243 (1996)

24. Diaz, H. F. \& Graham, N. E. Recent changes in tropical freezing heights and the role of sea surface temperature. Nature 383, 152-155 (1996).

25. Rangwala, I. \& Miller, J. R. Climate change in mountains: a review of elevation-dependent warming and its possible causes. Climatic Change. 114, 527-547 (2012).

26. Chapin, F. S. et al. Role of land-surface changes in arctic summer warming. Science 310, 657-660 (2005). 
27. Jeong, J-H. et al. Greening in the circumpolar high-latitude may amplify warming in the growing season. Clim. Dynam. 38, 1421-1431 (2012).

28. Fyfe, J. C. \& Flato, G. M. Enhanced climate change and its detection over the Rocky Mountains. J. Clim. 12, 230-243 (1999).

29. Rangwala, I., Miller, J. R. Russell, G. L. \& Xu, M. Using a global climate model to evaluate the influences of water vapor, snow cover and atmospheric aerosol on warming in the Tibetan Plateau during the twenty-first century. Clim. Dynam. 34, 859-872 (2010).

30. Ceppi, P., Scherrer, S. C. Fischer, A. M. \& Appenzeller, C. Revisiting Swiss temperature trends 1959-2008. Int. J. Climatol. 32, 203-213 (2010).

31. Scherrer, S., Ceppi, P., Croci-Maspoli, M. \& Appenzeller, C. Snow-albedo feedback and Swiss spring temperature trends. Theor. Appl. Climatol. 110, 509-516 (2012)

32. Hantel, M. \& Maurer C. The median winter snowline on the Alps. Met. Zeit. 20, 267-275 (2011).

33. Wunderle, S., Droz, M. \& Kleindienst, H. Spatial and temporal analysis of the snow line in the Alps based on NOAA-AVHRR data. Geogr. Helvet. 57, 170-183 (2002).

34. Minder, J. R., Durran, D. R. \& Roe, G. R. Mesoscale controls on the mountainside snow line. J. Atmos. Sci. 68, 2110-2127 (2011).

35. Hantel, M., Ehrendorfer, M. \& Haslinger, A. Climate sensitivity of snow cover duration in Austria. Int. J. Climatol. 20, 615-640 (2000).

36. Barnett, T. P. et al. Human-induced changes in the hydrology of the western United States. Science 319, 1080-1083 (2008).

37. Holtmeier, F-K. \& Broll, G. Sensitivity and response of northern hemisphere altitudinal and polar treelines to environmental change at landscape and local scales. Glob. Ecol. Biogeogr. 14, 395-410 (2005).

38. Jiang, D., Zhang, Y. \& Lang, X. Vegetation feedback under future global warming. Theor. Appl. Climatol. 106, 211-227 (2011).

39. Rikiishi, K. \& Nakasato, H. Height dependence of the tendency for reduction in seasonal snow cover in the Himalaya and the Tibetan Plateau region, 1966-2001. Ann. Glaciol. 43, 369-377 (2006).

40. Archer, D. R. \& Fowler, H. J. Spatial and temporal variations in precipitation in the Upper Indus Basin, global teleconnections and hydrological implications. Hydrol. Earth Syst. Sci. 8, 47-61 (2004).

41. Bhutiyani, M., Kale, V. \& Pawar, N. Climate change and the precipitation variations in the northwestern Himalaya: 1866-2006. Int. J. Climatol. 30, 535-548 (2010).

42. Kothawale, D., Munot, A. \& Kumar, K. K. Surface air temperature variability over India during 1901-2007, and its association with ENSO. Clim. Res. 42, 89-104 (2010).

43. Rangwala, I., Barsugli, J., Cozzetto, K., Neff, J. \& Prairie, J. Mid-21st century projections in temperature extremes in the southern Colorado Rocky Mountains from regional climate models. Clim. Dynam. 39, 1823-1840 (2012).

44. Vuille, M., Bradley, R., Werner, M. \& Keimig, F. 20th century climate change in the tropical Andes: observations and model results. Climatic Change 59, 75-99 (2003)

45. Liu, X., Cheng, Z., Yan, L. \& Yin, Z. Elevation dependency of recent and future minimum surface air temperature trends in the Tibetan Plateau and its surroundings. Glob. Planet. Change 68, 164-174 (2009).

46. Held, I. M. \& Soden, B. J. Robust responses of the hydrological cycle to global warming. J. Clim. 19, 5686-5699 (2006).

47. Rangwala, I., Miller, J. \& Xu, M. Warming in the Tibetan Plateau: possible influences of the changes in surface water vapor. Geophys. Res. Lett. 36, L06703 (2009)

48. Duan, A. \& Wu, G. Change of cloud amount and the climate warming on the Tibetan Plateau. Geophys. Res. Lett. 33, L22704 (2006)

49. Ruckstuhl, C., Philipona, R., Morland, J. \& Ohmura, A. Observed relationship between surface specific humidity, integrated water vapor, and longwave downward radiation at different altitudes. J. Geophys. Res. 112, D03302 (2007).

50. Naud, C. M., Miller, J. R. \& Landry, C. Using satellites to investigate the sensitivity of longwave downward radiation to water vapor at high elevations. J. Geophys. Res. 117, D05101 (2012).

51. Philipona, R., Dürr, B., Ohmura, A. \& Ruckstuhl, C. Anthropogenic greenhouse forcing and strong water vapor feedback increase temperature in Europe. Geophys. Res. Lett. 32, L19809 (2005)

52. Naud, C. M., Chen, Y., Rangwala, I. \& Miller, J. R. Sensitivity of downward longwave surface radiation to moisture and cloud changes in a high elevation region. J. Geophys. Res 118, 10072-10081 (2013).

53. Ohmura, A. On the cause of 'Fram' type seasonal change in diurnal amplitude of air temperature in polar regions. J. Climatol. 4, 325-338 (1984).

54. Ramanathan, V. \& Carmichael, G. Global and regional climate changes due to black carbon. Nature Geosci. 1, 221-227 (2008).

55. Bonasoni, P. et al. Atmospheric brown clouds in the Himalayas: first two years of continuous observations at the Nepal-Climate Observatory-Pyramid (5079 m). Atmos. Chem. Phys. 10, 4823-4885 (2010).
56. Vernier, J-P., Thomason, L. W. \& Kar, J. CALIPSO detection of an Asian tropopause aerosol layer. Geophys. Res. Lett. 38, L07804 (2011).

57. Lawrence, M. G. Asia under a high-level brown cloud. Nature Geosci. 4, 352-353 (2011).

58. Xu, B. et al. Black soot and the survival of Tibetan glaciers. Proc. Natl Acad. Sci. USA 106, 22114-22118 (2009).

59. Lau, W., Kim, M., Kim, K. \& Lee, W. Enhanced surface warming and accelerated snow melt in the Himalayas and Tibetan Plateau induced by absorbing aerosols. Environ. Res. Lett. 5, 025204 (2010).

60. Gautam, R., Hsu, N. C., Lau, W. K. \& Yasunari, T. Satellite observations of desert dust-induced Himalayan snow darkening. J. Geophys. Res. 40, 988-993 (2013).

61. Painter, T. H. et al. Impact of disturbed desert soils on duration of mountain snow cover. Geophys. Res. Lett. 34, L12502 (2007).

62. Santer, B. D. et al. Contributions of anthropogenic and natural forcing to recent tropopause height changes. Science 301, 479-483 (2003).

63. Hardy, D. R. in Encyclopedia of Snow, Ice and Glaciers (eds Singh, V. P., Singh, P. \& Haritashya, U. K.) 672-679 (Springer, 2011).

64. Holland, M. M. \& Bitz, C. M. Polar amplification of climate change in coupled models. Clim. Dynam. 21, 221-232 (2003).

65. Winton, M. Amplified Arctic climate change: what does surface albedo feedback have to do with it? Geophys. Res. Lett. 33, L03701 (2006).

66. Crook, J. A., Forster, P. M. \& Stuber, N. Spatial patterns of modeled climate feedback and contributions to temperature response and polar amplification. J. Clim. 24, 3575-3592 (2011).

67. Viviroli, D., Dürr, H. H., Messerli, B., Meybeck, M. \& Weingartner, R. Mountains of the world, water towers for humanity: typology, mapping, and global significance. Water Res. 43, W07447 (2007).

68. Bhutiyani, M., Kale, V. \& Pawar, N. Long-term trends in maximum, minimum and mean annual air temperatures across the Northwestern Himalaya during the twentieth century. Climatic Change 85, 159-177 (2007).

69. Chen, B., Chao, W. \& Liu, X. Enhanced climatic warming in the Tibetan Plateau due to doubling $\mathrm{CO}_{2}$ : a model study. Clim. Dynam. 20, 401-413 (2003).

70. Diaz, H. \& Eischeid, J. Disappearing 'alpine tundra' Köppen climatic type in the western United States. Geophys. Res. Lett. 34, L18707 (2007).

71. Gilbert, A. \& Vincent, C. Atmospheric temperature changes over the 20th century at very high elevations in the European Alps from englacial temperatures. Geophys. Res. Lett. 40, 2102-2108 (2013).

72. Hu, Y., Maskey, S. \& Uhlenbrook, S. Expected changes in future temperature extremes and their elevation dependency over the Yellow River source region. Hydrol. Earth System Sci. 17, 2501-2514 (2013).

73. Hu, Z., Zhang, C., Hu, Q. S. \& Tian, H. Temperature changes in Central Asia from 1979 to 2011 based on multiple datasets. J. Clim. 27, 1143-1167 (2014).

74. Im, E-S. \& Ahn, J-B. On the elevation dependency of present-day climate and future change over Korea from a high resolution regional climate simulation. J. Met. Soc. Japan 89, 89-100 (2011)

75. Li, Z. et al. Spatial and temporal trends of temperature and precipitation during 1960-2008 at the Hengduan Mountains, China. Quatern. Int. 236, 127-142 (2011).

76. Liu, X. \& Chen, B. Climatic warming in the Tibetan Plateau during recent decades. Int. J. Climatol. 20, 1729-1742 (2000)

77. Lu, A., Kang, S., Li, Z. \& Theakstone, W. Altitude effects of climatic variation on Tibetan Plateau and its vicinities. J. Earth Sci. 21, 189-198 (2010).

78. McGuire, C. R., Nufio, C. R., Bowers, M. D. \& Guralnick, R. P. Elevationdependent temperature trends in the Rocky Mountain Front Range: changes over a 56- and 20-year record. PLoS ONE 7, e44370 (2012).

79. Rangwala, I. \& Miller, J. R. Twentieth century temperature trends in Colorado's San Juan Mountains. Arct. Antarc. Alp. Res. 42, 89-97 (2010).

80. Seidel, D. \& Free, M. Comparison of lower-tropospheric temperature climatologies and trends at low and high elevation radiosonde sites. Climatic Change 59, 53-74 (2003).

81. Shrestha, A., Wake, C., Mayewski, P. \& Dibb, J. Maximum temperature trends in the Himalaya and its vicinity: an analysis based on temperature records from Nepal for the period 1971-94. J. Clim. 12, 2775-2786 (1999).

82. Tang, G. \& Arnone, J. A. Trends in surface air temperature and temperature extremes in the Great Basin during the 20th century from ground-based observations. J. Geophys. Res. Atmos. 118, 3579-3589 (2013).

83. Tao, J. et al. Elevation-dependent temperature change in the Qinghai-Xizang Plateau grassland during the past decade. Theor. Appl. Clim. 117, 61-71 (2013).

84. Vuille, M. \& Bradley, R. Mean annual temperature trends and their vertical structure in the tropical Andes. Geophys. Res. Lett. 27, 3885-3888 (2000).

85. You, Q. et al. Relationship between temperature trend magnitude, elevation and mean temperature in the Tibetan Plateau from homogenized surface stations and reanalysis data. Glob. Planet. Change 71, 124-133 (2010).

86. Zubler, E. M. et al. Localized climate change scenarios of mean temperature and precipitation over Switzerland. Clim. Change 125, 237-252 (2014). 


\section{Acknowledgements}

We acknowledge the Mountain Research Initiative for funding an international workshop in Payerbach Austria in April 2014 on elevation-dependent warming at which the idea for this paper was conceived and drafted.

\section{Author contributions}

N.P., R.S.B., H.F., E.P., I.R., S.N.W. and J.R.M. wrote and edited substantial sections of the main text; N.P., S.N.W., E.P. and N.F. wrote substantial sections of the supplementary material; S.W. helped with referencing; X.D.L. provided Fig. 1; N.P. conceived and M.B. provided Fig. 2; and I.R. provided Table 1. Other group members provided further insight, comments and editorial suggestions.

\section{Additional information}

Supplementary information is available in the online version of the paper. Reprints and permissions information is available online at www.nature.com/reprints.

Correspondence should be addressed to N.P.

\section{Competing financial interests}

The authors declare no competing financial interests.

N. Pepin ${ }^{1 \star}$, R. S. Bradley², H. F. Diaz ${ }^{3}$, M. Baraer4, E. B. Caceres ${ }^{5}$, N. Forsythe ${ }^{6}$, H. Fowler ${ }^{6}$, G. Greenwood $^{7}$, M. Z. Hashmi $^{8}$, X. D. Liu' ${ }^{9}$, J. R. Miller ${ }^{10}$, L. Ning ${ }^{11}$, A. Ohmura ${ }^{12}$, E. Palazzi ${ }^{13}$, I. Rangwala14, W. Schöner ${ }^{15}$, I. Severskiy ${ }^{16}$, M. Shahgedanova ${ }^{17}$, M. B. Wang ${ }^{18}$, S. N. Williamson ${ }^{19}$ and D. Q. Yang ${ }^{20}$

'Department of Geography, Buckingham Building, Lion Terrace, University of Portsmouth, Portsmouth PO1 3HE, UK. ${ }^{2} \mathrm{Climate}$ System Research Center, University of Massachusetts, Amherst, Massachusetts 01003, USA. ${ }^{3} \mathrm{CIRES}$, National Oceanic and Atmospheric Administration, Boulder, Colorado 80305 USA. " ETS-University of Quebec, Montreal, Quebec H3C 1K3, Canada. Instituto Nacional de Meterología e Hidrología, Loja, Iñaquito 700 y Corea, Ecuador. ${ }^{6}$ School of Civil Engineering and Geosciences, Newcastle University, Newcastle upon Tyne NE1 7RU, UK. ${ }^{7}$ University of Bern, 3012 Bern, Switzerland. ${ }^{8}$ Water Resources Section, Global Change Impact Studies Centre (GCISC), PO BOX 3022, Islamabad, Pakistan. ${ }^{9}$ SKLLQG, Institute of Earth Environment, Chinese Academy of Sciences and CAS Center for Excellence in Tibetan Plateau Earth Sciences, Beijing 100101, China. ${ }^{10}$ Department of Marine and Coastal Sciences, Rutgers University, New Jersey 08901, USA. "University of Massachusetts, Amherst, Massachusetts 01003, USA. ${ }^{2}$ ETH Zurich, 8092 Zurich, Switzerland. ${ }^{13}$ Institute of Atmospheric Sciences and Climate - National Research Council (ISAC-CNR), I-10133 Torino, Italy. ${ }^{14} \mathrm{CIRES/Western} \mathrm{Water}$ Assessment; Physical Sciences Division, NOAA ESRL, Boulder, Colorado 80305, USA. ${ }^{15}$ University of Graz, 8010 Graz, Austria. ${ }^{16}$ Institute of Geography, 050010 Almaty, Kazakhstan. ${ }^{17}$ University of Reading, Reading RG6 6AH, UK. ${ }^{18}$ Shanxi University, 030006 Taiyuan, China. ${ }^{19}$ University of Alberta, Edmonton, Alberta TG6 2R3, Canada. ${ }^{20}$ National Hydrology Research Centre, Environment Canada, S7N 3H5 Saskatoon, Canada. *e-mail: nicholas.pepin@port. 